\title{
Assessing the Hydrologic Performance of the Nonpoint Source Water Quality Assessment Decision Support Tool Using HSPF in Feitsui Reservoir Watershed
}

\author{
Shang-Lien Lo ${ }^{1 *}$, Sheng-Chung Huo ${ }^{1}$ and Ching-Sheng Yang ${ }^{2}$ \\ ${ }^{1}$ Graduate Institute of Environmental Engineering, National Taiwan University, Taiwan \\ ${ }^{2}$ Graduate Institute of Civil and Environmental Engineering, Mississippi State University, Taipei, Taiwan
}

\begin{abstract}
The accuracy of rainfall predictions in the EPA's BASINS (Better Assessment Science Integrating Point and Nonpoint Sources) decision support tool is affected by the sparse meteorological data contained in BASINS. The objectives of this study were improvement of using the entropy theory to supplement the precipitation data are significant when the watershed's meteorological station is either far away or not in a similar climatic region. When the station is nearby, using entropy theory to supplement the precipitation data produces similar results. And this study assessed the improvement of stream flow prediction of the Hydrological Simulation Program-FORTRAN (HSPF) model contained within BASINS using the hourly precipitation estimates in Feitsui reservoir watershed. Our results demonstrated consistent improvements of daily stream flow predictions in Feitsui reservoir watershed when precipitation data was incorporated into BASINS. Our analyses also showed that the stream flow improvements were mainly contributed by entropy theory to supplement precipitation data; partially due to the constraints of current BASINS-HSPF settings. However, entropy theory to supplement precipitation data did improve the base flow prediction. The entropy theory method showed 10.17 to 25.51 percent less error than the Thiessen polygon method and Arithmetic to supplement the rainfall data. And used entropy theory supplement the rainfall data to simulate stream flow that RMSE values between 58 and 182. This study demonstrates entropy theory to supplement precipitation has the potential to improve stream flow predictions, thus aid the water quality assessment in the nonpoint water quality assessment decision tool.
\end{abstract}

Keywords: Hydrological simulation program FORTRAN; BASINS; Entropy theory; Precipitation

\section{Introduction}

The Environmental Protection Agency (EPA) developed the BASINS (Better Assessment Science Integrating Point and Nonpoint Sources) decision support tool to assess water quality over large rangesized watersheds. The BASINS includes Hydrologic and water quality modeling with the Hydrological Simulation Program-Fortran (HSPF) models. HSPF involves managing large volumes of data [1]. So the accuracy of rainfall data in the BASINS decision support tool is affected by the sparse meteorological data contained in HSPF [2]. The erosional capacity of rainfall is an important natural factor because it represents a natural environmental constraint on land use and management [3]. The rainfall data are most important input for the simulation of watershed, instream, and water quality processes such as when using the HSPF model [4].

Effective watershed management strategies depend on the accuracy of the model results. To improve the accuracy of these results, a reconstruction of historical rainfall over a watershed is required. Muzylo [5] reviewed physically based rainfall interception models to supplement rainfall data. Dhanya [6] used a nonlinear prediction method for chaos identification and prediction. Mehrotra [7] used a stochastic modeling framework for multisite generation of daily rainfall in the generated rainfall sequences. The influence of rainfall spatial variability on the hydrological responses of watersheds has been a recurrent theme in hydrological research [8]. Chang [9] used fuzzy theory to simulate the precipitation; a membership function was applied to represent the relationship between areas lacking rainfall records and areas with rainfall gauges. Chen [10] used fuzzy sets to incorporate objective and subjective uncertainties to address water resources redistribution. Assessments of average annual precipitation and percentage weighting are necessary for hydrological for various water resources [11-13]. The accuracy of the modeling results greatly depends on the model parameters and the estimated input data. Radar approaches offer a good spatial description of precipitation but do not predict precipitation quantities with sufficient accuracy.

The entropy theory is a measure of the uncertainty associated with a random variable [14,15]. Zou [16] used an entropy method to determine the weights of evaluating indicators for water quality assessment. Agrawal [17] used the entropy method combined with the PDM model (Probability-Distributed Model, PDM ) to modify the rainfall parameter. Chen [18] used entropy to determine the optimum number and spatial distribution of rain gauge stations in catchments. The Shannon entropy is a measure of the average information uncertainty associated with a random variable [19]. Sonuga [20] applied the entropy principle to analyze rainfall and runoff. Maruyama [21] used Shannon's information entropy theory to assess disorders in intensity and apportionments of monthly rainfall over the period of one year in a given area. Deepak [17] used maximum entropy to develop a model to estimate weekly and monthly runoff for the

*Corresponding author: Shang-Lien Lo, Graduate Institute of Environmental Engineering, National Taiwan University, Taiwan, Tel: 886-2-23625373; Fax: 8862-23928830; E-mail: sllo@ntu.edu.tw

Received March 07, 2013; Accepted April 22, 2013; Published April 30, 2013

Citation: Lo SL, Huo SC, Yang CS (2013) Assessing the Hydrologic Performance of the Nonpoint Source Water Quality Assessment Decision Support Too Using HSPF in Feitsui Reservoir Watershed. Hydrol Current Res 4: 149 doi:10.4172/2157-7587.1000149

Copyright: (c) 2013 Lo SL, et al. This is an open-access article distributed under the terms of the Creative Commons Attribution License, which permits unrestricted use, distribution, and reproduction in any medium, provided the original author and source are credited. 
catchment of the Matatila Dam in India. Kottegoda [15,22] used an entropy model for the evaluation of variability in daily rainfall. This study was improvement of using the entropy theory to supplement the precipitation data, because accurate rainfall data are important for model calibration, such as HSPF. BASINS were developed to promote better assessment and integration of point and nonpoint sources in watershed and water quality management.

\section{Materials and Methods}

\section{Shannon entropy theory}

Shannon [23] developed the theory of informational entropy and introduced entropy as a measure of information. In this study, we used entropy theory to explain rainfall variability. In this study objection space $D\left(D=\left(d_{i j}\right)_{m n}\right), d_{i j}$ is the distance between rain gauge $i$ and rain gauge $j$ as shown in Eq. (1). $h_{i j}$ is the distance in elevation as shown in Eq. (1-1). In this study, there are six rainfall stations in the Feitsui reservoir watershed, so the Eq. (1) was $6 \times 6$ matrix $(m=6: n=6)$.

$$
\begin{aligned}
D(d) & =\left|\begin{array}{cccc}
d_{11} & d_{21} & \ldots & d_{m 1} \\
d_{12} & d_{22} & \ldots & d_{m 2} \\
: & : & \ldots & : \\
d_{1 n} & d_{2 n} & \ldots & d_{m n}
\end{array}\right| \\
D(h) & =\left|\begin{array}{cccc}
h_{11} & h_{21} & \ldots & h_{m 1} \\
h_{12} & h_{22} & \ldots & h_{m 2} \\
: & : & \ldots & : \\
h_{1 n} & h_{2 n} & \ldots & h_{m n}
\end{array}\right|
\end{aligned}
$$

Before using the entropy method, values of attribute $P_{i j}$ must be calculated by using Eq. (2). $P_{i j}$ is the probability mass function of outcome $d_{i j}$ shown in Eq. (2). $h_{i j}$ is the distance in elevation shown in Eq. (2-1). $P_{i j}$ contains both horizontal and vertical distances, the latter representing elevation. When two rainfall stations are close by, their rainfall conditions would be similar, whereas if two rainfall stations are far apart, their rainfall conditions are more likely to be different.

$$
\begin{aligned}
& P_{i j}(d)=\frac{d_{i j}}{\sum_{i=1}^{m} d_{i j}} \quad j=1,2, \ldots n \\
& P_{i j}(h)=\frac{h_{i j}}{\sum_{i=1}^{m} h_{i j}} \quad j=1,2, \ldots n
\end{aligned}
$$

In this study, horizontal and elevation values change the affect the weights of the rainfall stations. Where $d_{i j}$ is the distance between rain gauge $i$ and rain gauge $j$. Eq. (2) shows that $d_{i j}$ can be changed to $h_{i j}$, where $h_{i j}$ is the distance in elevation between rain gauge $i$ and rain gauge $j \cdot p$ is the order of the horizontal parameter, and $q$ is the order of the elevation parameter. Traditional methods assign weights of either zero or one. Using the entropy theory to supplement the rainfall data, increased $p$ values and $q$ values control the attribute $P_{i j}$. The values of the exponents $p$ and $q$ control the horizontal and elevation parameters. When exponents $p$ and $q$ are incorporated into equation (2), the equation becomes Eq. (3) and Eq. (3-1).

$$
\begin{aligned}
& P_{i j}(d)=\frac{d_{i j}{ }^{-p}}{\sum_{i=1}^{m}\left(d_{i j}^{-p}\right)} \quad j=1,2, \ldots n \\
& P_{i j}(h)=\frac{h_{i j}^{-q}}{\sum_{i=1}^{m}\left(h_{i j}^{-q}\right)} \quad j=1,2, \ldots n
\end{aligned}
$$

Shannon (1948) defined the entropy, $H$ for a set of probabilities $P_{i j}$ as in Eq. (4). In this study, we focus on the problem of recovering and processing information. The entropy theory can be written explicitly as shown in Eq. (4).

$$
H_{i}=\sum_{i=1}^{m} P_{i j} \log \frac{1}{P_{i j}} \quad j=1,2, \ldots n
$$

Combining Eq. (3) and Eq. (4) results in Eq. (5).

$$
\begin{aligned}
& H_{i}(d)=\sum_{i=1}^{m}\left(\frac{d_{i j}{ }^{-p}}{\sum_{i=1}^{m}\left(d_{i j}{ }^{-p}\right)}\right) \log \frac{1}{\left(\frac{d_{i j}{ }^{-p}}{\sum_{i=1}^{m}\left(d_{i j}{ }^{-p}\right)}\right)} \quad j=1,2, \ldots n \\
& H_{i}(h)=\sum_{i=1}^{n}\left(\frac{h_{i j}{ }^{-q}}{\sum_{i=1}^{m}\left(h_{i j}{ }^{-q}\right)}\right) \log \frac{1}{\left(\frac{h_{i j}{ }^{-q}}{\sum_{i=1}^{m}\left(h_{i j}{ }^{-q}\right)}\right)} \quad j=1,2, \ldots n
\end{aligned}
$$

The Shannon (1948) definition of entropy weight values is obtained from Eq. (6), which defines the weight $\left(w_{i}\right)$. By studying the elements in a set, horizontal distances and elevation differences affect the probability of rainfall. Weights are subject to the range $0 \leq H_{i} \leq 1$.

$$
w_{i}=\frac{1-H_{i}}{\sum_{i=1}^{m}\left(1-H_{i}\right)}
$$

where $w_{i}$ is the rainfall weight.

This study used the weighted average method as defined by Eq. (7) 
Rainfall data were simulated by substituting the definition of entropy weight in Eq. (6) into the Eq. (7).

$X_{\text {it }}$ represents the observations, and $Y$ represents the simulated values. The $t$ value is the rainfall series.

$$
Y=\sum_{i=1}^{m} X_{i t} w_{i} \quad t=1,2, \ldots . Z
$$

Substitute Eq. (6) into Eq. (7) to obtain Eq. (8).

$$
Y=\sum_{i=1}^{m} X_{i t}\left(\frac{1-H_{i}}{\sum_{i=1}^{m}\left(1-H_{i}\right)}\right)
$$

Because the rainfall data supplement not only with horizontal distance of the rainfall $\mathrm{g}$ station, but also with elevation was an important influence factor, therefore, this study used the entropy theory and combines the fuzzy theory estimation precipitation. As a result, it is more rational to make the weight of every precipitation station rain fall materials assign.

\section{Fuzzy theory}

The fuzzy method utilizes membership functions to describe standards in relation to different uses. The fuzzy membership function was used in this paper to illustrate the relative importance of each rainfall gauge station in the Feitsui reservoir watershed. This method has been shown to be capable of finding a solution that achieves the optimal balance between the two objective values, namely the membership function of horizontal distance and elevation. Their membership functions are separately defined by Eq. (9) and Eq. (10), where $d$ and $h$ are the order of horizontal distances and the order of elevation differences, respectively [24]. A description of the class of optimization method based on the entropy theory of using a fuzzy weight function follows.

Mathematically, let $U=\left\{d_{11}, d_{12}, \ldots . d_{m n}\right\}$ be a universal set of objects $d$, where $d$ is the variable of horizontal distances, and $V=\left\{h_{11}, h_{12}, \ldots . . h_{m n}\right\}$ be a general set of objects $h$, where $h$ is the variable of elevation. Then, fuzzy sets $Y_{d}$ in $U$ and $Y_{h}$ in $V$ are defined as in Eq. (9) and Eq. (10).

$$
\begin{aligned}
& Y_{d}=\left\{d, u_{Y_{d}}(d)\right\} \forall d \in U \\
& Y_{h}=\left\{h, u_{Y_{h}}(h)\right\} \forall h \in V
\end{aligned}
$$

where $u_{Y_{d}}(d)$ is called the membership grade of $d$ in $u_{Y_{d}}$ , the membership function of horizontal distances, which represents the relative importance of each surrounding rainfall gauge due to the effect of horizontal distances. $u_{Y_{h}}(h)$ is the membership grade of $h$ in $u_{Y_{h}}$, the membership function of elevation differences, which shows the relative importance of each vicinal gauge station based on the effect of differences in elevation. The rainfall stations in the control area are the high effect coefficient weight of the rainfall stations. The value of the membership function $u$ varies from 0 to 1 and represents the degree of importance and influence from non-membership to fullmembership. $u_{Y_{d}}(d)$ and $u_{Y_{h}}(h)$ are by definition the control area of the watershed shown in Figure 1 and are set by the conditions shown in Eq.(11) and Eq.(12).

$$
\begin{aligned}
& u_{Y_{d}}(d)=\left\{\begin{array}{cc}
1 & 0 \leq d \leq d_{\text {end }} \\
d^{-p} & d>d_{\text {end }}
\end{array}\right. \\
& u_{Y_{h}}(h)=\left\{\begin{array}{cc}
1 & 0 \leq h \leq h_{\text {end }} \\
h^{-q} & h>h_{\text {end }}
\end{array}\right.
\end{aligned}
$$

In this study, we combined the horizontal and elevation factors to establish the scale. These membership functions are significant and define the composite fuzzy set as $W=\left\{z_{11}, z_{12}, \ldots \ldots z_{m n}.\right\}$. The corresponding rainfall station fuzzy set is shown in Eq. (13), where $u_{Y}(z)$ is the membership grade of $z$ in $Y$. The membership degree of horizontal distances is combined with the membership degree of elevation differences, so $u_{Y}(z)$ can be redefined as:

$$
Y=\left\{z, u_{Y}(z)\right\} \forall z \in W
$$

The above equations are combined to further define these membership functions and to represent the integral effect of horizontal distances and elevation differences. The resulting equation is shown as follows: the membership function $u_{Y}(z)$ is a function of $u_{Y_{d}}(d)$ and $u_{Y_{h}}(h)$ as defined in Eq. (14).

$$
u_{Y}(z)=u_{Y}(d, h)
$$

Because $u_{Y_{d}}(d)$ and $u_{Y_{h}}(h)$ have the same characteristics, we use the square root of the sum of the square of $u_{Y_{d}}(d)$ and $u_{Y_{h}}(h)$ , as shown in Eq. (15).

$$
u_{Y}(d, h)=\sqrt{u_{Y_{d}}(d)^{2}+u_{Y_{h}}(h)^{2}}
$$

Substituting Eq. (15) in Eq. (6) gives the entropy weight as shown in Eq. (16). Furthermore, the substitution of Eq. (16) into Eq. (4) uses weight mean to simulate precipitation as shown in Eq. (17) and then a

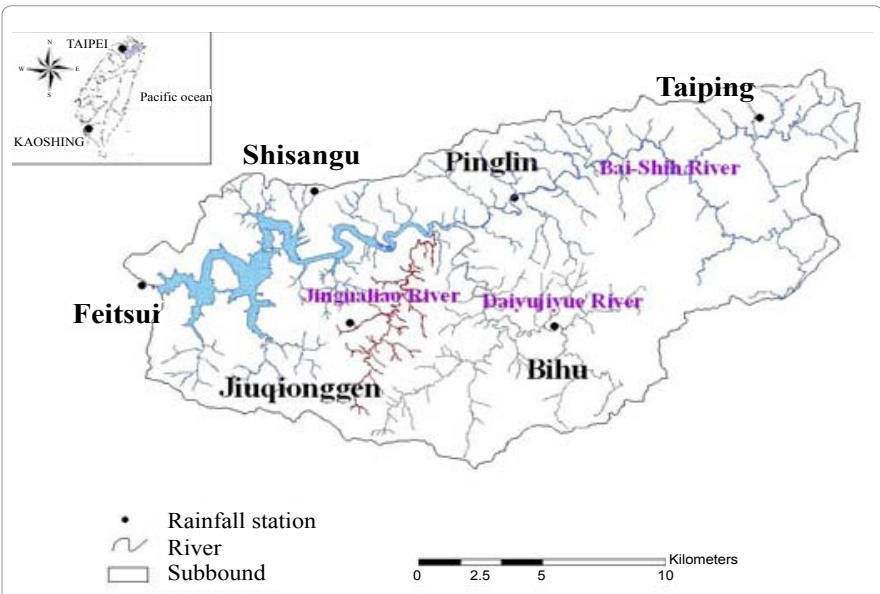

Figure 1: Rainfall gauge stations in the Feitsui reservoir watershed. 
fuzzy set $\widetilde{H}_{i}$ that can be defined as:

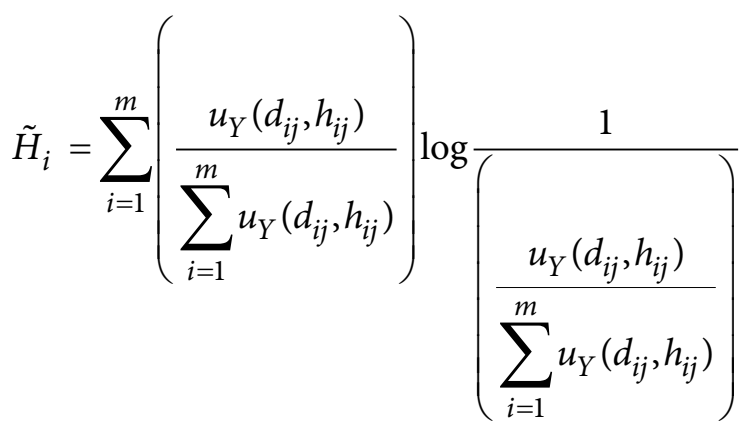

$j=1,2 \ldots n$

The estimated precipitation can then be estimated by:

$$
Y=\sum_{i=1}^{m} X_{i t} \frac{1-\tilde{H}_{i}}{\sum_{i=1}^{m}\left(1-\tilde{H}_{i}\right)}
$$

\section{HSPF model}

This study first supplement the hourly rainfall data in Feitsui reservoir watershed and input the simulate data to the Hydrological Simulation Program-FORTRAN (HSPF) evaluates improvement of the daily flow prediction. The HSPF simulates the hydrologic and associated water quality processes. The model simulates the time response of the watershed based on the hydrologic. Calibration is an iterative process used in establishing the most suitable values for some model parameters. The HSPF model is a physical model that incorporates GIS data [25]. Bicknell [25] is simulating land surface and subsurface hydrologic and water quality processes. Root mean square error (RMSE) was used to determine the accuracy of the estimated results. The utility of this quantitative model was that it could demonstrate the accuracy of the observed and simulated values. The smaller the simulated values, the closer the values were to the actual observed values. The RMSE equation is shown in Eq. (18), which provides a better indication of the capability of the model simulation.

$$
R M S E=\sqrt{\left(\frac{\left.\sum_{i=1}^{m}\left(Y-X_{i t}\right)^{2}\right)}{T}\right)} t=1,2 \ldots Z
$$

where T=aggregate number, $Y$ =simulative data, $X_{i t}=$ field data.

\section{Results and Discussion}

As stated previously, the Feitsui reservoir watershed is located in northern Taiwan and has a drainage area of $303 \mathrm{~km} 2$. There are six rainfall stations in the Feitui reservoir watershed, namely Pinglin, Shisangue, Feitsui, Jiuqionggen, Bihu and Taiping. Table 1 lists the horizontal distances and elevation differences between the rainfall gauge stations in the Feitsui reservoir watershed. The location of these six rainfall gauge stations is shown below in Figure 1. And there are three rivers in the Feitsui reservoir watershed, namely Bai-Shih river, Jingualiao River, and Daiyujiyue River. There are six rainfall stations in Feitsui reservoir, and we used five rainfall stations to estimate other rainfall data and simulate flows and No-point pollution. The principal conclusions of this study are as follows.

The arithmetic average method and the Thiessen polygon were used to simulate the precipitation. The data generated by the arithmetic average method were compared with the data generated by the entropy method. Therefore, the entropy of the weight variables and the entropy of the different probability distributions could be developed to deal with rainfall values for many rain gauge stations. Table 2 summarizes the percent error generated by the three methods. The rainfall data simulation was performed for the time period 01/01/2007-31/12/2007. Using the entropy method by RMSE were 1.52, 1.28, 1.98, 1.27, 1.81, and 1.91 at the Pinglin, Shisangue, Feitsui, Jiuqionggen, Bihu and Taiping rainfall stations, respectively, and are shown in Figure 2.

The main effects of the order of the distances in the entropy method, the variable " $p$ " in formula (3), are rainfall characteristics and horizontal distances between rainfall stations and the locations of the stations. The results show that the value of the variable " $p$ " is close to 8 for the Feitsui rainfall stations, between 8 and 9 for the Jiuqionggen and Bihu rainfall stations and between 13 and 24 for the Shisangue, Pinglin and Taiping rainfall stations. As shown in Figure 1, the Feitsui rainfall stations are located near towns and the variability and roughness of the topography is less than in the area surrounding the Pinglin and Taiping rainfall stations. Hence, the values of the variable " $p$ " are more uniform and not as extreme.

Table 3 shows that use of the arithmetic average method on precipitation interpolation usually causes larger RMSE than any other

\begin{tabular}{|l|c|c|c|c|c|c|}
\hline Rainfall station & Pinglin & Shisangu & Feitsui & Jiuqionggen & Bihu & Taiping \\
\hline Horizontal distance $(\mathrm{m})$ & & & & & & \\
\hline Pinglin & 0 & & & & & \\
\hline Shisangu & 6729 & 0 & & & & \\
\hline Feitsui & 14011 & 7760 & 0 & & & \\
\hline Jiuqionggen & 7654 & 3684 & 6769 & 0 & & \\
\hline Bihu & 6468 & 11558 & 17007 & 10317 & 0 & \\
\hline Taiping & 12377 & 18883 & 26382 & 19953 & 12514 & 0 \\
\hline Elevation differences & $(\mathrm{m})$ & & & & & \\
\hline Pinglin & 0 & & & & & \\
\hline Shisangu & 320 & 0 & & & & \\
\hline Feitsui & 8 & 328 & 0 & & & \\
\hline Jiuqionggen & 168 & 152 & 176 & 0 & & \\
\hline Bihu & 176 & 144 & 184 & 8 & 0 & \\
\hline Taiping & 250 & 70 & 254 & 82 & 74 & 0 \\
\hline
\end{tabular}

Table 1: Horizontal distances and elevation differences between rainfall stations in the Feitsui reservoir watershed.

\begin{tabular}{|c|c|c|c|}
\hline Rainfall station & Entropy weights & $p$ & $q$ \\
\hline Pinglin & 0.168 & 15 & 24 \\
\hline Shisangu & 0.170 & 24 & 1 \\
\hline Feitsui & 0.168 & 9 & 1 \\
\hline Jiuqionggen & 0.165 & 8 & 25 \\
\hline Bihu & 0.165 & 9 & 25 \\
\hline Taiping & 0.164 & 13 & 24 \\
\hline
\end{tabular}

Table 2: Estimates of the statistical parameters. 
methods, and the Thiessen polygon method is usually not the optimal method to truly describe rainfall spatial variation. The results also indicate that the entropy method is more suitable than the arithmetic average method and the Thiessen polygon method to describe the spatial variation of rainfall. The analytical data show that the estimated error in the precipitation generated by the entropy method was considerably reduced.; the error percentages at the rainfall gauge stations were between 10 and 25, respectively, and were lower than those obtained from the arithmetic average method and Thiessen. When the entropy theory was used in conjunction with fuzzy theory to predict rainfall, it enabled an even more accurate assessment or determination of the potential availability of water resources. The proposed method can be successfully applied to reassess the rainfall of the Feitui reservoir catchment. Inherent limitations to the method involve the use of rainfall records for supplement rainfall data.

The hydrologic simulation was performed for the time period $01 / 01 / 2007-31 / 12 / 2007$. For this time period, hourly data for the flow were available from the hydrometric station of basin. In this study, the calibration was performed manually for the time period 01/01/2007-31/12/2007 and the obtained parameters were used for model validation for the time period $01 / 1 / 2007-31 / 12 / 2007$. The first step in the calibration process was the calculation of the hydrologic parameters for basin, at the exit. The flow results obtained by using the HSPF are compared to the field data in Table 4 . The results obtained by using the empirical hydrologic model for the hydrologic years 2007 are in good agreement with the observed field data. Final results and the reliability of the conceptual model. Based on these results, the average annual flow in Bai-Shih river was estimated to be $6249 \mathrm{~m}^{3} /$ year which is in very good agreement with the observed value of $6818 \mathrm{~m}^{3} /$ year (error of $4 \%$ ). The annual hydrologic mass balance for the system and the Jingualiao River during the calibration time period was estimated as follows. The Jingualiao River flow at the exit point of the basin outlet was $1508 \mathrm{~m}^{3} /$ year. The watershed estimated flow was $1283 \mathrm{~m}^{3} /$ year (error of 15\%). Daiyujiyue River was estimated to be $4854 \mathrm{~m}^{3} /$ year. The Daiyujiyue flow at the outlet point was $4937 \mathrm{~m}^{3} /$ year(error of $2 \%$ ). In order to compare the field data with the simulation results in Table 4.

During the flood of 2007 simulations phosphate-P concentrations are shown in Table 5. Bai-Shih river, Jingualiao River, and Daiyujiyue River the "R" values were $0.737,0.771$ and 0.81 .Although the simulations give generally good results, there are some discrepancies. The simulated phosphate-P concentration values were $8592(\mathrm{~kg} / \mathrm{y})$, $1591(\mathrm{~kg} / \mathrm{y})$ and $5451(\mathrm{~kg} / \mathrm{y})$ at the Bai-Shih river, Jingualiao River, and Daiyujiyue River. More specifically, in order to improve the simulation

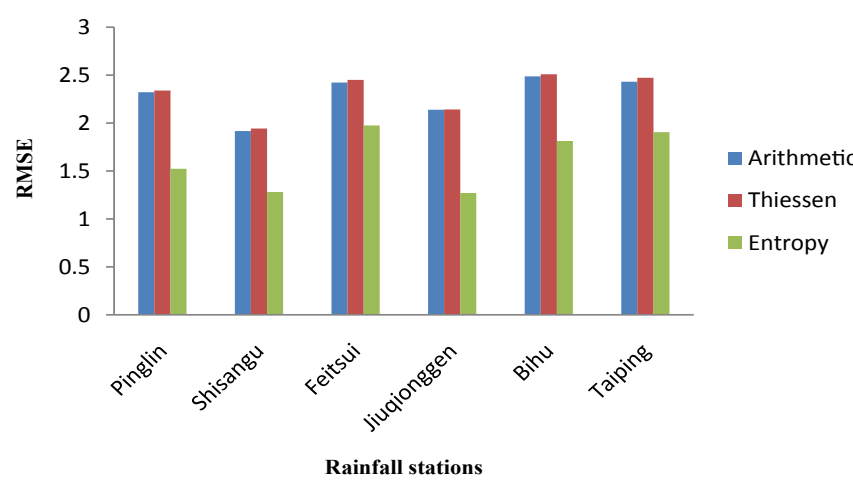

Figure 2: Relative estimated error of precipitation by several methods at each rainfall station in the Feitsui reservoir watershed.

\begin{tabular}{|c|c|c|c|c|c|}
\hline & Arithmetic & Thiessen & Entropy & Error & Error \\
\hline $\begin{array}{c}\text { Rainfall Gauge } \\
\text { Station }\end{array}$ & RMSE & RMSE & RMSE & $\begin{array}{c}\text { arithmetic and } \\
\text { entropy } \% \\
\text { difference) }\end{array}$ & $\begin{array}{c}\text { Thiessen and } \\
\text { entropy } \% \\
\text { difference) }\end{array}$ \\
\hline Pinglin & 2.32 & 2.34 & 1.52 & 20.74 & 21.10 \\
\hline Shisangu & 1.92 & 1.94 & 1.28 & 19.90 & 20.53 \\
\hline Feitsui & 2.42 & 2.45 & 1.98 & 10.17 & 10.72 \\
\hline Jiuqionggen & 2.14 & 2.14 & 1.27 & 25.47 & 25.51 \\
\hline Bihu & 2.49 & 2.51 & 1.81 & 15.67 & 16.11 \\
\hline Taiping & 2.43 & 2.47 & 1.91 & 12.13 & 12.94 \\
\hline
\end{tabular}

Table 3: Comparison of the percent error of precipitation between the observed and simulated data, using RMSE.

\begin{tabular}{|c|c|c|c|}
\hline River & $\begin{array}{c}\text { observation flows } \\
\left(\mathrm{m}^{3} / \mathrm{y}\right)\end{array}$ & simulation flows $\left(\mathrm{m}^{3} / \mathrm{y}\right)$ & RMSE \\
\hline Bai-Shih river & 6818 & 6561 & 182 \\
\hline Jingualiao River & 1509 & 1283 & 159 \\
\hline Daiyujiyue River & 4937 & 4854 & 58 \\
\hline
\end{tabular}

Table 4: Comparison of the observation flows and simulation flows, using RMSE.

\begin{tabular}{|c|c|c|c|}
\hline River & simulation flows $\left(\mathrm{m}^{3} / \mathrm{y}\right)$ & $\mathrm{R}$ & simulation $\mathrm{po}^{4-}(\mathrm{kg} / \mathrm{y})$ \\
\hline Bai-ShihRiver & 6249 & 0.737 & 8592 \\
\hline Jingualiao River & 1148 & 0.771 & 1591 \\
\hline Daiyujiyue River & 4612 & 0.81 & 5451 \\
\hline
\end{tabular}

Table 5: Values of $\mathrm{R}$ for the flow and simulation $\mathrm{po}^{4-}$.

results and supplement the rainfall data and input the HSPF models to simulate the flows and no-point pollution. As expected, the rainfall data plays an important role regarding the final form of the hydrograph and the agreement of the simulated hydrograph peaks to the observed field data. The results obtained in the present study showed a very good agreement with field measurements.

\section{Conclusions}

The aim of this study was the development of a framework to model the hydrologic processes in a complex hydrogeological river basin such as the Feitsui Basin. The framework model presented in this study, in contrast to other integrated hydrologic models, takes into consideration all the components that affect the rainfall process. The main contributions of the present work includes the combination of the HSPF model, the development of an supplement rainfall data model. The above models can become useful to the hydrology developments for a better description of the complex processes that take place in the physical system. Future research should focus on incorporating measurements of the natural rainfall properties of the particular region, including duration and intensity, and their effects on precipitation characteristics for the better management of water supplies.

\section{References}

1. USEPA (2001) Better Assessment Science Integrating point and Nonpoin Sources BASINS Version 3.0 User's Manual. US Environmental Protection Agency.

2. Lee S, Ni-Meister W, Toll D, Nigro J, Guiterrez-Magness A, et al. (2010) Assessing the hydrologic performance of the EPA's nonpoint source water quality assessment decision support tool using North American Land Data Assimilation System (NLDAS) products. J Hydrol 387: 212-220.

3. Angulo-Martinez M, Begueria S (2009) Estimating rainfall erosivity from daily precipitation records: A comparison among methods using data from the Ebro Basin (NE Spain). J Hydrol 379: 111-121.

4. Angelica L, Gutierrez M (2004) Accuracy evaluation of rainfall disaggregation methods. J Hydrologic Eng 9: 71-78.

5. Muzylo A, Llorens P, Valente F, Kziezr JJ, Domingo F, et al. (2009) A review of rainfall interception modeling. Journal of hydrology 370: 191-206. 
Citation: Lo SL, Huo SC, Yang CS (2013) Assessing the Hydrologic Performance of the Nonpoint Source Water Quality Assessment Decision Support Tool Using HSPF in Feitsui Reservoir Watershed. Hydrol Current Res 4: 149. doi:10.4172/2157-7587.1000149

6. Dhanya C T, Nagesh Kuma D (2010) Nonlinear ensemble prediction of chaotic daily rainfall. Adv Water Resour 33: 327-347.

7. Mehrotra R, Sharma A (2007) Preserving low-frequency variability in generated daily rainfall sequences. J Hydrol 35: 105-120.

8. Ratnasingham Srikanthan, Geoffrey GS Pegram (2009) A nested multisite daily rainfall stochastic generation model. J. Hydrol 371: 142-153.

9. Chang CL, Lo SL, Yu SL (2005) Applying fuzzy theory and genetic algorithm to interpolate precipitation. Journal of hydrology 314: 92-104.

10. Chen HW, Chang NB (2010) Using fuzzy operators to address the complexity in decision making of water resources redistribution in two neighboring river basins. Adv Water Resour 33: 652-666.

11. Şen Z (1998) Average areal precipitation by percentage weighting polygon method. J Hydrol Eng 1: 69-72.

12. Şen Z, Habib Z (1998) Point cumulative semivariogram of areal precipitation in mountainous regions. J Hydrol 205: 81-91.

13. Şen Z, Habib Z (2000) Spatial precipitation assessment with elevation by using Point Cumulative Semivariogram Technique. Water Resour Manag 14: $311-$ 325.

14. Chen YC, Chiang W, Yeh HC (2008) Rainfall network design using kriging and entropy. Hydrol Process 22: 340-346.

15. Golan A, Judge G, Perloff JM (1996) A maximum entropy approach to recovering Information from multinomial response data. J Am Stat Assoc 91: 841-853.

16. Zou ZH, Yun Y, Sun JN (2006) Entropy method for determination of weight of evaluating indicators in fuzzy synthetic evaluation for water quality assessment J Environ Sci (China) 18: 1020-1023.

17. Agrawal D, Singh JK, Kumar A (2005) Maximum entropy-based conditional probability distribution runoff model. Biosystems Enginerring 90: 103-113.

18. Chen SZ, Wang XJ, Zhao XJ (2008) An attribute recognition model based on entropy weight for evaluating the quality of groundwater sources. J China Univ Mining \& Technol 18: 72-75.

19. Kawachi T, Maruyama T, Singh VP (2001) Rainfall entropy for delineation of water resources zones in Japan. Journal of hydrology 246: 36-44.

20. Sonuga JO (1976) Entropy principle applied to the rainfall-runoff process. Hydrol 30: 81-94.

21. Maruyama T, Kawachi T, Singh VP (2005) Entropy-based assessment and clustering of potential water resources availability. Journal of hydrology 309 104-113.

22. Kottegoda NT, Natale L, Raiteri E (2004) Some considerations of periodicity and persistence in daily rainfalls. Journal of hydrology 296: 23-37.

23. Shannon CE (1948) A mathematical theory of communication. Bell Syst Tech J 27: 379-423, 623-656.

24. Chang CL, Lo SL, Yu SL (2006) The parameter optimization in the inverse distance method by genetic algorithm for estimating precipitation. Environ Monit Assess 117: 145-155.

25. Bicknell BR, Imhoff JS, Kittle JL, Jobes TH, Donigian AS (2001) Hydrologica Simulation Program-FORTRAN (HSPF): User's Manual-Version 12. US Environmental Protection Agency. 